\title{
Central nervous system involvement in adult patients with diffuse large B-cell lymphoma: Influence of rituximab
}

\author{
BING CAO ${ }^{1,2}$, XIAOYAN ZHOU ${ }^{2,3}$, DONGMEI JI ${ }^{1,2}$, JUNNING CAO ${ }^{1,2}$, YE GUO ${ }^{1,2}$, QUNLING ZHANG ${ }^{1,2}$, \\ XIANGHUA WU ${ }^{1,2}$, JUNMIN LI $^{4}$, JIANMIN WANG ${ }^{5}$, FANGYUAN CHEN $^{6}$, \\ $\mathrm{CHUN}_{\mathrm{WANG}^{7}, \text { SHANHUA }^{2} \mathrm{ZU}^{8} \text { and XIAONAN HONG }}{ }^{1,2}$ \\ ${ }^{1}$ Department of Medical Oncology, Fudan University Shanghai Cancer Center; ${ }^{2}$ Department of Oncology, \\ Shanghai Medical College, Fudan University; ${ }^{3}$ Department of Pathology, Fudan University Shanghai Cancer Center; \\ ${ }^{4}$ Department of Hematology, Ruijin Hospital Affiliated to Shanghai Jiaotong University School of Medicine; \\ ${ }^{5}$ Department of Hematology, Changhai Hospital Affiliated to Second Military Medical University; \\ ${ }^{6}$ Department of Hematology, Renji Hospital Affiliated to Shanghai Jiaotong University School of Medicine; \\ ${ }^{7}$ Department of Hematology, The First People's Hospital Affiliated to Shanghai Jiaotong University; \\ ${ }^{8}$ Department of Hematology, Zhongshan Hospital Fudan University, Shanghai, P.R. China
}

Received March 2, 2012; Accepted June 7, 2012

DOI: $10.3892 / \mathrm{ol} .2012 .755$

\begin{abstract}
CHOP (cyclophosphamide, doxorubicin, vincristine and prednisone)-like chemotherapy, in combination with rituximab (R-CHOP-like), improves outcome in patients with diffuse large B-cell lymphoma (DLBCL). We aimed to investigate the impact of rituximab on central nervous system (CNS) disease in adult patients. We studied 315 patients (aged 18-60 years old) from six hospitals between July 2003 and May 2008. All patients received CHOP-like $(n=165)$ or R-CHOP-like $(n=150)$ regimen every 3 weeks. With a median follow-up of 3.69 years, 10 patients (3.17\%) developed CNS disease. The cumulative risk of CNS occurrence was not significantly different between the two treatment groups $(\mathrm{P}=0.871)$. We conclude that the addition of rituximab did not reduce the risk of CNS disease in adult patients with DLBCL.
\end{abstract}

\section{Introduction}

Involvement of the central nervous system (CNS) is an infrequent yet often fatal complication of diffuse large B-cell lymphoma (DLBCL). It is widely accepted that due to the low incidence of CNS relapse, prophylactic measures in all DLBCL patients cannot be recommended.

The addition of rituximab to $\mathrm{CHOP}$ (cyclophosphamide, adriamycin, vincristine and prednisone; R-CHOP) has been

Correspondence to: Professor Xiaonan Hong, Department of Medical Oncology, Fudan University Shanghai Cancer Center, 270 Dongan Road, Shanghai 200032, P.R. China

E-mail: xnhong0086@163.com

Key words: central nervous system, diffuse large B-cell lymphoma, rituximab reported to significantly prolong event-free survival and overall survival (OS) in DLBCL patients (1-5). It is controversial whether the improvement in outcome is in part due to the impact of rituximab on CNS events. Early data indicate no benefit (6) or protective effects against CNS relapse in elderly patients $(7,8)$.

We analyzed CNS events occurring in adult patients with DLBCL treated with CHOP-like or R-CHOP-like regimen at six university hospitals in Shanghai, China. The aim was to evaluate the impact of rituximab on CNS events.

\section{Patients and methods}

Patients. This retrospective study was conducted using data from six university hospitals in Shanghai between July 2003 and May 2008. Clinical information was gathered by review of medical charts. Ethics approval for this study and informed consent from the patients were obtained. Patients were enrolled if they were $\geq 18$ years of age, newly diagnosed with DLBCL and treated with at least four cycles of CHOP-like or R-CHOP-like regimen every 3 weeks. Patients with human immunodeficiency virus, CNS involvement at diagnosis, receiving any CNS prophylaxis during the clinical course, primary mediastinal large B-cell lymphoma and incomplete clinical information were excluded from the study and their information was not recorded during the data collection process. The CHOP-like regimens consisted of cyclophosphamide, 600-750 mg/m², day 1; anthracycline (doxorubicin, $40-50 \mathrm{mg} / \mathrm{m}^{2}$, day 1 ; or epirubicin, $60-70 \mathrm{mg} / \mathrm{m}^{2}$, day 1 ; or pirarubicin, $40-50 \mathrm{mg} / \mathrm{m}^{2}$, day 1 ); vincristine, $1.4 \mathrm{mg} / \mathrm{m}^{2}$ (up to a maximal dose of $2 \mathrm{mg}$ ), day 1 (or vindesin, $2 \mathrm{mg} / \mathrm{m}^{2}$, day 1); and prednisone, $80-100 \mathrm{mg}$, days 1-5. Rituximab was administered at a dose of $375 \mathrm{mg} / \mathrm{m}^{2}$ on day 1 or 2 of each cycle.

CNS disease. In our study, patients with CNS recurrence after achieving systemic $\mathrm{CR} / \mathrm{CRu} / \mathrm{PR}$ and patients with spread of 
disease to the CNS during first-line therapy were included. The diagnosis was based on the combination of clinical symptoms, radiological findings and the presence of lymphoma cells in the spinal fluid.

Statistical analysis. The primary endpoint was the time to CNS disease, defined as the time from the diagnosis of lymphoma to disease progression in the CNS, or CNS relapse after $\mathrm{CR} / \mathrm{CRu} / \mathrm{PR}$. The secondary endpoint was survival following CNS disease, defined as the time from the diagnosis of CNS disease until death from any cause. Progression-free survival (PFS) was measured from the time of diagnosis to the time of first disease progression or relapse or death resulting from any cause. OS was calculated from the time of initial diagnosis to the time of death from any cause or of last follow-up. Time to CNS disease, survival following CNS disease, PFS and OS were estimated according to the Kaplan-Meier method. Baseline characteristics were compared between the treatment groups using the Chi-square test and Fisher's exact test when appropriate. Statistical analysis was conducted using the SPSS 16.0 software package (Chicago, IL, USA).

\section{Results}

Patient characteristics. A total of 472 consecutive patients with DLBCL who fulfilled the inclusion criteria were identified, and 315 adult patients (aged 18-60 years old) were the subjects of this retrospective analysis. Patient characteristics by treatment are listed in Table I, with no statistically significant differences observed between the arms. A total of 165 patients were treated with CHOP-like therapy and 150 patients received R-CHOP-like treatment. In our study, the CHOP-like and R-CHOP-like therapies were administered in parallel time periods, as rituximab was approved as the first line therapy for DLBCL after 2006 in China. Patients decided whether to undergo R-CHOP-like or CHOP-like treatment.

The median age was 49 years for the CHOP-like group and 50 years for the R-CHOP-like group. Of the 315 patients, $258(81.90 \%)$ achieved a CR following treatment; $79.39 \%$ receiving CHOP-like and $84.67 \%$ in the R-CHOP-like group. The 5-year OS (79.7 versus $64.5 \%, \mathrm{P}=0.012$ ) was superior in the R-CHOP-like group.

CNS disease in CHOP- and $\mathrm{R}$-CHOP-like-treated patients. With a median follow-up of 3.69 years, 10 patients (3.17\%) developed CNS disease (Table II). A total of 5 of the 165 patients (3.03\%) treated with CHOP-like, and 5 of the 150 patients $(3.33 \%)$ administered R-CHOP-like therapy, experienced a CNS event. In 5 patients (100\%), CNS disease occurred after a complete remission had been achieved in the R-CHOP-like group compared with 3 patients $(60 \%)$ in the CHOP-like group. In the remaining 2 patients (40\%), CNS disease was diagnosed together with progressive disease. Overall, 4 patients (80\%) experienced a CNS event without systemic disease whatever the treatment arm. One patient had a first relapse in other sites prior to the CNS in the CHOP-like group, and one patient had a first relapse in the CNS before other sites in the R-CHOP-like group. In each group, the primary site was the lymph node in one patient $(20 \%)$ and an extranodal site in four patients (80\%). Table III shows the
Table I. Clinical characteristics of all patients.

\begin{tabular}{|c|c|c|c|}
\hline Clinical factor & $\begin{array}{l}\text { CHOP-like } \\
\quad(n=165)\end{array}$ & $\begin{array}{c}\text { R-CHOP-like } \\
\quad(n=150)\end{array}$ & P-value \\
\hline \multicolumn{4}{|l|}{ Age (years) } \\
\hline Median (range) & $49(18-60)$ & $50(18-60)$ & \\
\hline Gender & & & 0.723 \\
\hline Male & 88 & 77 & \\
\hline Female & 77 & 73 & \\
\hline B symptom & & & 0.200 \\
\hline Yes & 41 & 47 & \\
\hline No & 124 & 103 & \\
\hline Stage & & & 0.078 \\
\hline I-II & 89 & 66 & \\
\hline III-IV & 76 & 84 & \\
\hline ECOG & & & 0.916 \\
\hline $0-1$ & 148 & 134 & \\
\hline $2-4$ & 17 & 16 & \\
\hline LDH & & & 0.469 \\
\hline Normal & 89 & 87 & \\
\hline Elevated & 76 & 63 & \\
\hline Extranodal sites & & & 0.126 \\
\hline$<2$ & 130 & 107 & \\
\hline$\geq 2$ & 35 & 43 & \\
\hline IPI & & & 0.854 \\
\hline $0-2$ & 142 & 128 & \\
\hline $3-5$ & 23 & 22 & \\
\hline aaIPI & & & 0.487 \\
\hline $0-1$ & 116 & 100 & \\
\hline $2-3$ & 49 & 50 & \\
\hline Bone marrow & & & 0.226 \\
\hline No & 151 & 131 & \\
\hline Yes & 14 & 19 & \\
\hline
\end{tabular}

CHOP, cyclophosphamide, doxorubicin, vincristine and prednisone; R-CHOP, rituximab with CHOP; ECOG, Eastern Cooperative Oncology Group; LDH, lactate dehydrogenase; IPI, International Prognostic Index; aaIPI, age-adjusted IPI.

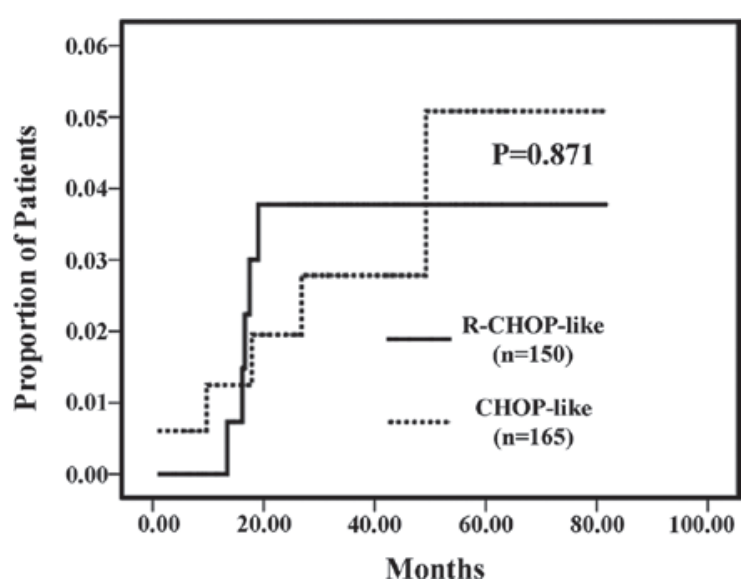

Figure 1. Cumulative risk of CNS disease in patients treated with CHOP-like and R-CHOP-like. CNS, central nervous system; CHOP, cyclophosphamide, doxorubicin, vincristine and prednisone; R-CHOP, rituximab with CHOP. 
Table II. Characteristics of patients with CNS relapse $(n=10)$.

\begin{tabular}{|c|c|c|}
\hline Clinical factor & $\begin{array}{l}\text { CHOP-like } \\
\qquad(n=5)\end{array}$ & $\begin{array}{l}\text { R-CHOP-like } \\
\quad(n=5)\end{array}$ \\
\hline \multicolumn{3}{|l|}{ Gender } \\
\hline Male & 2 & 4 \\
\hline Female & 3 & 1 \\
\hline Age (years), median (range) & $55(40-59)$ & $43(43-51)$ \\
\hline \multicolumn{3}{|l|}{ B symptom } \\
\hline Yes & 2 & 1 \\
\hline No & 3 & 4 \\
\hline \multicolumn{3}{|l|}{ Stage } \\
\hline I-II & 2 & 4 \\
\hline III-IV & 3 & 1 \\
\hline \multicolumn{3}{|l|}{ ECOG } \\
\hline $0-1$ & 5 & 4 \\
\hline $2-4$ & 0 & 1 \\
\hline \multicolumn{3}{|l|}{$\mathrm{LDH}$} \\
\hline Normal & 2 & 5 \\
\hline Elevated & 3 & 0 \\
\hline \multicolumn{3}{|l|}{ Extranodal sites } \\
\hline$<2$ & 3 & 4 \\
\hline$\geq 2$ & 2 & 1 \\
\hline \multicolumn{3}{|l|}{ IPI } \\
\hline $0-2$ & 3 & 4 \\
\hline $3-5$ & 2 & 1 \\
\hline \multicolumn{3}{|l|}{ aaIPI } \\
\hline $0-1$ & 3 & 4 \\
\hline $2-3$ & 2 & 1 \\
\hline \multicolumn{3}{|l|}{ Bone marrow } \\
\hline No & 5 & 5 \\
\hline Yes & 0 & 0 \\
\hline \multicolumn{3}{|l|}{ Primary site } \\
\hline Lymph node & 1 & 1 \\
\hline Testis & 0 & 3 \\
\hline Bone & 0 & 1 \\
\hline Ileocecal junction & 1 & 0 \\
\hline Lung & 1 & 0 \\
\hline Adrenal gland & 1 & 0 \\
\hline Breast & 1 & 0 \\
\hline \multicolumn{3}{|l|}{ Site of CNS relapse } \\
\hline Parenchymal & 4 & 5 \\
\hline Leptomeninges & 1 & 0 \\
\hline \multicolumn{3}{|l|}{ Response to initial treatment } \\
\hline Complete response & 3 & 5 \\
\hline Partial response & 0 & 0 \\
\hline No response or progressive disease & 2 & 0 \\
\hline \multicolumn{3}{|l|}{ Relapse in CNS versus systemic } \\
\hline First relapse in CNS only & 4 & 4 \\
\hline $\begin{array}{l}\text { First relapse in CNS } \\
\text { simultaneously with other sites }\end{array}$ & 0 & 0 \\
\hline First relapse in other sites then CNS & 1 & 0 \\
\hline First relapse in CNS then other sites & 0 & 1 \\
\hline
\end{tabular}

CHOP, cyclophosphamide, doxorubicin, vincristine and prednisone; R-CHOP, rituximab with CHOP; ECOG, Eastern Cooperative Oncology Group; LDH, lactate dehydrogenase; IPI, International Prognostic Index; aaIPI, age-adjusted IPI; CNS, central nervous system.
Table III. CNS relapse according to specific initial extranodal sites.

\begin{tabular}{lcc}
\hline & \multicolumn{2}{c}{ CNS relapse/involvement } \\
\cline { 2 - 3 } Initial extranodal site & CHOP-like & R-CHOP-like \\
\hline Testis & $0 / 5$ & $3 / 7$ \\
Breast & $1 / 10$ & $0 / 5$ \\
Bone & $0 / 4$ & $1 / 4$ \\
Ileocecal junction & $1 / 4$ & $0 / 1$ \\
Lung & $1 / 2$ & $0 / 0$ \\
Adrenal gland & $1 / 3$ & $0 / 0$ \\
\hline
\end{tabular}

CHOP, cyclophosphamide, doxorubicin, vincristine and prednisone; $\mathrm{R}-\mathrm{CHOP}$, rituximab with CHOP; CNS, central nervous system.

number of patients with CNS relapse according to specific initial extranodal sites in all patients.

The median time between diagnosis and CNS disease was 17.02 months (range, 0.8-49.23) in patients who developed CNS disease and the estimated median survival following CNS disease was 15.23 months. However, the difference for patients treated without or with rituximab is not significant for the time to CNS disease (17.83 vs. 16.60 months, $\mathrm{P}=0.356$ ) and survival following CNS disease (2.93 vs. 28.73 months, $\mathrm{P}=0.083)$. A total of five patients $(100 \%)$ in the R-CHOP-like group relapsed $>1$ year following diagnosis (range, 13.4018.97 months); by contrast, three patients $(60 \%)$ in the CHOP-like group relapsed $>1$ year from diagnosis (range, 0.80-49.23 months in 5 patients).

Comparing the two treatment groups, the cumulative risk of CNS occurrence was not significantly different (log-rank test, $\mathrm{P}=0.871$; Fig. 1 ).

\section{Discussion}

CNS relapse is a rare but often fatal event for patients with DLBCL and the incidence ranges from 5 to $25 \%$ (8). Currently, the addition of rituximab to CHOP is widely accepted as the standard chemotherapy for DLBCL, and has significantly prolonged event-free survival and OS in adult patients (5). We aimed to investigate whether the improvement in outcome is in part due to the impact of rituximab on CNS events. In the present study, we reported CNS events in 315 adult patients with DLBCL treated with CHOP-like or R-CHOP-like regimen. With a median follow-up of 3.69 years, 10 patients (3.17\%) developed CNS disease, 5 in the R-CHOP-like and 5 in the CHOP-like group. No significant difference for patients treated without or with rituximab was observed in the time to CNS disease (17.83 vs. 16.60 months, $\mathrm{P}=0.356$ ) and survival following CNS disease (2.93 vs. 28.73 months, $\mathrm{P}=0.083$ ).

Rituximab did not influence the risk of CNS relapse in our study $(\mathrm{P}=0.871)$. The Groupe d'Etude des Lymphomes de l'Adulte (GELA) analyzed 399 elderly patients with DLBCL treated with eight cycles of CHOP-21 with or without rituximab, and showed no influence of rituximab on the risk of CNS relapse (6). An analysis of another study, in which 
375 patients with DLBCL received CHOP-21 or R-CHOP21 , demonstrated no significant difference in the incidence of CNS involvement (9). Likewise, Tai et al (10) in a study involving 499 patients with DLBCL also did not find any significant difference in the CNS recurrence rates between patients who received CHOP or R-CHOP therapies. On the contrary, the German High-Grade Non-Hodgkin Lymphoma Study Group (DSHNHL) reported that rituximab modestly decreased the risk of CNS occurrence in the RICOVER-60 trial of CHOP-14 or R-CHOP-14 in 1,222 elderly patients with aggressive CD20-positive lymphoma (2-year incidence, 6.9 vs. $4.1 \%$; $\mathrm{P}=0.043$ ) (7). A study from Japan concluded that rituximab had a protective effect against CNS relapse in multivariate analysis in 403 patients with DLBCL ( $\mathrm{P}=0.027)$ (11). A study from the British Columbia Cancer Agency suggested that rituximab reduced the risk of CNS relapse in 435 patients with DLBCL (3-year risk, 9.7 vs. 6.4\%; $\mathrm{P}=0.085$ ) (8). The differences in patient populations and the small number of cases relapsed in the CNS in certain studies likely account for the discrepancy in the effect of rituximab on the risk of CNS relapse among these studies. Taken together, these data indicate that treatment with $\mathrm{R}-\mathrm{CHOP}$ results in a moderate decrease of CNS disease, at best.

Although there is evidence that patients with CNS lymphoma have a disrupted blood/brain barrier (7), initial pharmacokinetic studies show that levels of rituximab in the cerebrospinal fluid (CSF) are approximately $0.1 \%$ of matched serum levels following an intravenous administration dose (12). Intrathecal (IT) administration of rituximab to increase the concentration of rituximab in the CSF has been demonstrated to be safe and effective in animal models $(12,13)$, several case reports (14-18) and a phase I trial (19). Nonetheless, the prophylactic and therapeutic effects of rituximab on CNS events remains elusive.

Although numerous risk factors for CNS disease have been suggested, there is no clear consensus on which patients with DLBCL should receive CNS prophylaxis. Given the rarity of CNS relapse in DLBCL patients and the risk of toxicity caused by CNS prophylaxis, it is agreed that the use of CNS prophylaxis in all patients is not justified. Currently, highrisk groups, including those with involvement of the testis, breast, bone marrow, sinus or orbital cavity, have been recommended prophylactic IT methotrexate (MTX) in most centers. However, there has been no randomized study to indicate that this strategy is effective in reducing CNS involvement. By contrast, IT MTX may not have a protective effect against CNS relapse, according to certain data $(7,8,10,20)$. Abramson et al, in a retrospective study including 65 patients with DLBCL and CNS risk factors receiving intravenous high-dose MTX as CNS prophylaxis concurrent with $\mathrm{CHOP}$ or $\mathrm{R}-\mathrm{CHOP}$ regimen, found that this approach may be associated with a low risk of CNS occurrence in high-risk patients (21), but prospective assessment is needed.

We recognized several limitations in our study, including the use of retrospective data, not being part of a clinical trial, the small number of patients developing CNS events and potential selection bias.

In summary, the addition of rituximab to CHOP chemotherapy does not reduce the risk of CNS disease in adult patients with DLBCL, according to our data. Further research is needed to identify more effective strategies to prevent CNS recurrence.

\section{Acknowledgements}

We would like to thank Shanghai Lymphoma Research Group for supporting this study.

\section{References}

1. Habermann TM, Weller EA, Morrison VA, et al: Rituximab-CHOP versus CHOP alone or with maintenance rituximab in older patients with diffuse large B-cell lymphoma. J Clin Oncol 24: 3121-3127, 2006.

2. Coiffier B, Lepage E, Briere J, et al: CHOP chemotherapy plus rituximab compared with $\mathrm{CHOP}$ alone in elderly patients with diffuse large-B-cell lymphoma. N Engl J Med 346: 235-242, 2002.

3. Feugier P, Van Hoof A, Sebban C, et al: Long-term results of the R-CHOP study in the treatment of elderly patients with diffuse large B-cell lymphoma: a study by the Groupe d'Etude des Lymphomes de l'Adulte. J Clin Oncol 23: 4117-4126, 2005.

4. Pfreundschuh M, Schubert J, Ziepert M, Schmits R, Mohren M, Lengfelder E, Reiser M, Nickenig C, Clemens M, Peter N, Bokemeyer C, Eimermacher H, Ho A, Hoffmann M, Mertelsmann R, Trümper L, Balleisen L, Liersch R, Metzner B, Hartmann F, Glass B, Poeschel V, Schmitz N, Ruebe C, Feller AC and Loeffler M; German High-Grade Non-Hodgkin Lymphoma Study Group (DSHNHL): Six versus eight cycles of bi-weekly CHOP-14 with or without rituximab in elderly patients with aggressive CD20+ B-cell lymphomas: a randomised controlled trial (RICOVER-60). Lancet Oncol 9: 105-116, 2008.

5. Pfreundschuh $M$, Trümper L, Osterborg A, Pettengell R, Trneny M, Imrie K, Ma D, Gill D, Walewski J, Zinzani PL, Stahel R, Kvaloy S, Shpilberg O, Jaeger U, Hansen M, Lehtinen T, López-Guillermo A, Corrado C, Scheliga A, Milpied N, Mendila M, Rashford M, Kuhnt E and Loeffler M; MabThera International Trial Group: CHOP-like chemotherapy plus rituximab versus CHOP-like chemotherapy alone in young patients with good prognosis diffuse large-B-cell lymphoma: a randomised controlled trial by the MabThera International Trial (MInT) Group. Lancet Oncol 7: 379-391, 2006.

6. Feugier P, Virion JM, Tilly H, et al: Incidence and risk factors for central nervous system occurrence in elderly patients with diffuse large-B-cell lymphoma: influence of rituximab. Ann Oncol 15: 129-133, 2004.

7. Boehme V, Schmitz N, Zeynalova S, Loeffler M and Pfreundschuh M: CNS events in elderly patients with aggressive lymphoma treated with modern chemotherapy (CHOP-14) with or without rituximab: an analysis of patients treated in the RICOVER-60 trial of the German high-grade non-Hodgkin lymphoma study group (DSHNHL). Blood 113: 3896-3902, 2009.

8. Villa D, Connors JM, Shenkier TN, Gascoyne RD, Sehn LH and Savage KJ: Incidence and risk factors for central nervous system relapse in patients with diffuse large B-cell lymphoma: the impact of the addition of rituximab to CHOP chemotherapy. Ann Oncol 21: 1046-1052, 2010.

9. Yamamoto W, Tomita N, Watanabe R, et al: Central nervous system involvement in diffuse large B-cell lymphoma. Eur J Haematol 85: 6-10, 2010.

10. Tai WM, Chung J, Tang PL, et al: Central nervous system (CNS) relapse in diffuse large B cell lymphoma (DLBCL): pre- and post-rituximab. Ann Hematol 90: 809-818, 2011.

11. Shimazu Y, Notohara K and Ueda Y: Diffuse large B-cell lymphoma with central nervous system relapse: prognosis and risk factors according to retrospective analysis from a singlecenter experience. Int J Hematol 89: 577-583, 2009.

12. Rubenstein JL, Combs D, Rosenberg J, et al: Rituximab therapy for CNS lymphomas: targeting the leptomeningeal compartment. Blood 101: 466-468, 2003.

13. Reff ME, Carner K, Chambers KS, et al: Depletion of B cells in vivo by a chimeric mouse human monoclonal antibody to CD20. Blood 83: 435-445, 1994.

14. Pels H, Schulz H, Manzke O, Hom E, Thall A and Engert A: Intraventricular and intravenous treatment of a patient with refractory primary CNS lymphoma using rituximab. J Neurooncol 59: 213-216, 2002. 
15. Pels H, Schulz H, Schlegel U and Engert A: Treatment of CNS lymphoma with the anti-CD20 antibody rituximab: experience with two cases and review of the literature. Onkologie 26: 351-354, 2003

16. Schulz H, Pels H, Schmidt-Wolf I, Zeelen U, Germing U and Engert A: Intraventricular treatment of relapsed central nervous system lymphoma with the anti-CD20 antibody rituximab. Haematologica 89: 753-754, 2004.

17. Antonini G, Cox MC, Montefusco E, et al: Intrathecal anti-CD20 antibody: an effective and safe treatment for leptomeningeal lymphoma. J Neurooncol 81: 197-199, 2007.

18. Liu CY, Teng HW, Lirng JF, Chiou TJ, Chen PM and Hsiao LT: Sustained remission and long-term survival of secondary central nervous system involvement by aggressive B-cell lymphoma after combination treatment of systemic high-dose chemotherapy. Leuk Lymphoma 49: 2018-2021, 2008.
19. Rubenstein JL, Fridlyand J, Abrey L, et al: Phase I study of intraventricular administration of rituximab in patients with recurrent CNS and intraocular lymphoma. J Clin Oncol 25: 1350-1356, 2007.

20. Bernstein SH, Unger JM, Leblanc M, Friedberg J, Miller TP and Fisher RI: Natural history of CNS relapse in patients with aggressive non-Hodgkin's lymphoma: a 20-year follow-up analysis of SWOG 8516 - the Southwest Oncology Group. J Clin Oncol 27: 114-119, 2009.

21. Abramson JS, Hellmann M, Barnes JA, et al: Intravenous methotrexate as central nervous system (CNS) prophylax is is associated with a low risk of CNS recurrence in high-risk patients with diffuse large B-cell lymphoma. Cancer 116: 4283-4290, 2010. 